\title{
Removal of some organic dyes by acid-treated spent bleaching earth
}

\begin{abstract}
Acid treated spent bleaching earth was prepared by treating spent bleaching earth, a waste material from the palm oil industry, with $20 \%$ sulphuric acid and heated at $350^{\circ} \mathrm{C}$ for three hours. This material can efficiently sorb a variety of organic dyes especially reactive and acid dyes, with maximum sorption capacity in the order of $2 i 3300 \mathrm{mg}$ gi 1 . The applicability of both the Langmuir and Freundlich isotherms to the experimental data indicates that both physicosorption and chemisorption were involved in the sorption process.
\end{abstract}

Keyword: Acid treated spent bleaching earth; Reactive dyes; Acid dyes; Sorption 